\title{
GOMMENTARY
}

\section{US Federal Policies Should Better Support the Primary Care Physician Workforce}

Julie Phillips, MD, MPH; Jennifer Edwards-Johnson, DO; Andrea Wendling, MD

(Fam Med. 2018;50(1):7-9.)

doi: 10.22454/FamMed.2018.784272

$\mathbf{T}$ he specialty distribution of graduate medical education in the United States is largely unregulated. Although Medicare provides funding to residencies, hospitals are not required to educate physicians in specific specialties, even those critically needed for the public's health. Over the last 2 decades, specialty and subspecialty graduate medical education has increased substantially. Over the same time period, although the number of residents matching in primary care has increased modestly, these gains have been offset by the increasing percentage of these residents who subspecialize, creating a net loss of primary care graduate medical education. ${ }^{1-5}$

Most medical students and residents also desire specialization in fields outside of primary care, which has resulted in an imbalanced workforce. The nation has a substantial need for primary care providers, mental health providers, and general surgeons. In many places, we have a surplus of medical and surgical specialists, which contributes to costly and uncoordinated care. ${ }^{6-11}$

In this context of shortage and surplus, several federal programs play key roles in shaping the primary care physician workforce in particular. How effective are these programs in helping us meet our nation's needs?

The National Health Service Corps (NHSC) was founded with the expressed purpose of encouraging health professionals to provide primary care in underserved communities. Two major programs exist: a scholarship program and a loan repayment program. These programs have been very successful. As of 2011, more than 2,000 NHSC primary care physicians were caring for underserved communities in the United States. ${ }^{12}$ Most states have similar loan repayment programs. ${ }^{13} \mathrm{Un}$ fortunately, many communities that would benefit from NHSC sponsorship have not been able to obtain it-funds are limited and the demand for physicians is still great. ${ }^{12}$

There is little evidence that the opportunity for NHSC loan repayment influences students to choose primary care, although it probably has some effect. Unfortunately, students often perceive the available amount of loan repayment as small relative to their debt levels. The NHSC scholarship program, however, pays total medical school tuition costs and provides a stipend for students who commit to primary care careers, offering students a substantial financial benefit. ${ }^{14}$ The program also promotes diversity in the primary care workforce: underrepresented minority family medicine residents are twice as likely to have enrolled. ${ }^{15}$

An NHSC scholarship may help students with a strong primary care interest at the beginning of medical school to maintain that interest. However, this program has two major limitations. First, the terms of repayment for students who do not practice primary care in an underserved community are extremely punitive, making the program suitable only for students who are very certain of their primary care interest. ${ }^{16}$ Secondly, only $16 \%$ of students who apply for scholarship funds receive

From the Sparrow-Michigan State University Family Medicine Residency Program (Drs Phillips and EdwardsJohnson), and Michigan State University College of Human Medicine (Dr Wendling). 
awards. ${ }^{15}$ These limitations represent missed opportunities to recruit and retain students interested in primary care early in their medical school years, when the NHSC could have a formative effect on Corps members.

Another key federal policy also shapes our workforce. The US J-1 visa programs allow non-US citizens who are graduates of international medical schools (noncitizen IMGs) to complete graduate medical education in the United States; most then settle in the United States for practice. ${ }^{17}$ The problem is that many J-1 visa programs allow waivers for both specialists and primary care physicians, and there has been a trend toward more specialist physicians in state-sponsored programs. ${ }^{18}$ In addition, although J-1 visa programs generally require physicians who stay in the United States after residency to practice in underserved communities, the $\mathrm{H}-1 \mathrm{~B}$ visa program does not even require underserved practice. ${ }^{19,20}$ Although IMGs are more likely to practice as generalists than US graduates, most do not practice primary care. ${ }^{19,21-24}$ Thus, these physicians help relieve the primary care physician shortage, but they also exacerbate the specialist surplus. Furthermore, although many believe IMGs are more likely to practice in underserved settings, evidence does not clearly support this. ${ }^{17,21,23,25,26}$

Finally, in recent years, the Public Service Loan Forgiveness (PSLF) program has become an important part of the workforce landscape. PSLF allows graduates who work for nonprofit organizations and make regular student loan payments for 10 years to have their remaining federal student debt forgiven. The program's authors envisioned it as a way for teachers, social workers, and other middle-class professionals to have relief from high student loan debt. However, because most hospitals are nonprofit organizations, many employed physicians will also qualify. A recent comprehensive analysis found that one-fourth of 2014 graduates plan to apply for PSLF loan forgiveness. ${ }^{27}$

Is the PSLF program helping the primary care workforce, or is it causing harm? On one hand, the program provides hope for many students who are interested in primary care, but carry significant debt at high interest rates. Some students with high debt do not believe primary care careers, or other careers in medicine with relatively lower income potential, are feasible for them. ${ }^{28}$ Many students with the strongest interest in primary care, including underrepresented minority students and students from disadvantaged backgrounds, also have the highest debt levels. ${ }^{29,30}$ The PSLF thus serves an important function in reassuring these students.

On the other hand, the PSLF is expensive and inefficient. The program is projected to cost approximately $\$ 314$ million in physician loan forgiveness for the class of 2014, approximately seven times the loan forgiveness cost of the NHSC. ${ }^{27}$ Most of this support will be given to specialists working for nonprofit hospitals and health systems. The program does not favor or incentivize physicians who care for underserved populations, and it provides greater financial advantages to physicians with prolonged training periods-who are typically specialists. $^{27}$

What should we do as family medicine educators? Clearly, we should not advocate for unregulated expansion of graduate medical education, although as the competition for residency positions becomes more intense, this rallying cry has become popular. Instead, we should encourage our health policy to "work smarter." Each of the federal policies described above could be more efficient and effective with reforms that favor primary care of underserved populations. Programs with proven benefits, like the NHSC, should be expanded. The surplus of specialists, where it exists, should be recognized as a potentially harmful force that drives up costs and dilutes limited resources. Family medicine, as a discipline, must strategically support evidence-based workforce policy that will improve the health of the country.

CORRESPONDING AUTHOR: Address correspondence to Dr Phillips, Sparrow-MSU Family Medicine Residency Program, 1215 East Michigan Ave, Suite 245, Lansing, MI 48912. 616-234-2672. Fax: 616-234-2638. Julie.phillips@hc.msu.edu..

\section{References}

1. Jolly P, Erikson C, Garrison G. U.S. graduate medical education and physician specialty choice. Acad Med. 2013;88(4):468-474.

2. Holt KD, Miller RS, Philibert I, Nasca TJ. Patterns of Change in ACGME-Accredited Residency Programs and Positions: Implication for the Adequacy of GME Positions and Supply of Physicians in the United States. J Grad Med Educ. 2014;6(2):399-403.

3. Weida NA, Phillips RL Jr, Bazemore AW. Does graduate medical education also follow green? Arch Intern Med. 2010;170(4):389-390.

4. Coutinho AJ, Klink K, Wingrove P, Petterson S, Phillips RL Jr, Bazemore A. Changes in Primary Care Graduate Medical Education Are Not Correlated With Indicators of Need: Are States Missing an Opportunity to Strengthen Their Primary Care Workforce? Acad Med. 2017;92(9):1280-1286.

5. Salsberg E, Rockey PH, Rivers KL, Brotherton SE, Jackson GR. US residency training before and after the $1997 \mathrm{Bal}-$ anced Budget Act. JAMA. 2008;300(10):1174-1180. 
6. Macinko J, Starfield B, Shi L. The contribution of primary care systems to health outcomes within Organization for Economic Cooperation and Development (OECD) countries, 1970-1998. Health Serv Res. 2003;38(3):831-865.

7. Macinko J, Starfield B, Shi L. Quantifying the health benefits of primary care physician supply in the United States. Int J Health Serv. 2007;37(1):111-126.

8. Bazemore A, Petterson S, Peterson LE, Phillips RL Jr. More Comprehensive Care Among Family Physicians is Associated with Lower Costs and Fewer Hospitalizations. Ann Fam Med. 2015;13(3):206-213.

9. Saultz JW, Lochner J. Interpersonal continuity of care and care outcomes: a critical review. Ann Fam Med. 2005;3(2):159166.

10. California Healthcare Foundation. California Physicians: Surplus or Scarcity? http://www.chcf.org/ /media/MEDIA $\% 20$ LIBRARY\%20Files/PDF/PDF\%20C/PDF\%20CaliforniaPhysiciansSurplusSupply2014.pdf. Published 2014. Accessed October 26, 2017.

11. Weiner JP. Expanding the US medical workforce: global perspectives and parallels. BMJ. 2007;335(7613):236-238.

12. Pathman DE, Konrad TR. Growth and changes in the National Health Service Corps (NHSC) workforce with the American Recovery and Reinvestment Act. J Am Board Fam Med. 2012;25(5):723-733.

13. Pathman DE, Goldberg L, Konrad TR, Morgan JC. State repayment programs for health care education loans. JAMA. 2013;310(18):1982-1984.

14. National Health Service Corps Scholarship Program. https:// nhsc.hrsa.gov/downloads/costs.pdf. Accessed September 28 , 2017.

15. Phillips J, Peterson LE, Fang B, Kovar-Gough I, Phillips RL How Many Graduating Family Medicine Residents Have Chosen Financial Support for Service Commitments? Fam Med. 2017;49(8):626-629.

16. National Health Service Corps Scholarship Program Application and Program Guidance. 2017; https://nhsc.hrsa. gov/downloads/spapplicationguide.pdf. Accessed October 13, 2017.

17. Mick SS, Lee SY, Wodchis WP. Variations in geographical distribution of foreign and domestically trained physicians in the United States: 'safety nets' or 'surplus exacerbation'? Soc Sci Med. 2000;50(2):185-202.

18. Patterson DG, Keppel G, Skillman SM, Berry C, Daniel C, Doescher MP. Recruitment of Non-U.S. Citizen Physicians to Rural and Underserved Areas through Conrad State 30 J-1 Visa Waiver Programs. 2015; http://depts.washington. edu/uwrhrc/uploads/RHRC_FR148_Patterson.pdf. Accessed October 13, 2017.

19. Fordyce MA, Doescher MP, Chen FM, Hart LG. Osteopathic physicians and international medical graduates in the rural primary care physician workforce. Fam Med. 2012;44(6):396403.
20. US Citizenship and Immigration Services. H-1B Specialty Occupations, DOD Cooperative Research and Development Project Workers, and Fashion Models. https://www.uscis.gov/ working-united-states/temporary-workers/h-1b-specialtyoccupations-dod-cooperative-research-and-developmentproject-workers-and-fashion-models. Accessed October 13, 2017.

21. Fink KS, Phillips RL Jr, Fryer GE, Koehn N. International medical graduates and the primary care workforce for rural underserved areas. Health Aff (Millwood). 2003;22(2):255262.

22. Boulet JR, Norcini JJ, Whelan GP, Hallock JA, Seeling SS. The international medical graduate pipeline: recent trends in certification and residency training. Health Aff (Millwood). 2006;25(2):469-477.

23. Mullan F, Politzer RM, Davis CH. Medical migration and the physician workforce. International medical graduates and American medicine. JAMA. 1995;273(19):1521-1527.

24. van Zanten M, Boulet JR. Medical education in the Caribbean: quantifying the contribution of Caribbean-educated physicians to the primary care workforce in the United States. Acad Med. 2013;88(2):276-281.

25. Thompson MJ, Hagopian A, Fordyce M, Hart LG. Do international medical graduates (IMGs) "fill the gap" in rural primary care in the United States? A national study. J Rural Health. 2009;25(2):124-134.

26. Hart LG, Skillman SM, Fordyce M, Thompson M, Hagopian A, Konrad TR. International medical graduate physicians in the United States: changes since 1981. Health Aff (Millwood). 2007;26(4):1159-1169.

27. Friedman AB, Grischkan JA, Dorsey ER, George BP. Forgiven but not Relieved: US Physician Workforce Consequences of Changes to Public Service Loan Forgiveness. J Gen Intern Med. 2016;31(10):1237-1241.

28. Phillips JP, Wilbanks DM, Salinas DF, Doberneck DM. Educational Debt in the Context of Career Planning: A Qualitative Exploration of Medical Student Perceptions. Teach Learn Med. 2016;28(3):243-251.

29. Phillips JP, Petterson SM, Bazemore AW, Phillips RL. A retrospective analysis of the relationship between medical student debt and primary care practice in the United States. Ann Fam Med. 2014;12(6):542-549.

30. Phillips JP, Weismantel DP, Gold KJ, Schwenk TL. Medical student debt and primary care specialty intentions. Fam Med. 2010;42(9):616-622. 